\title{
RELATÓRIO DE ESTÁGIO SUPERVISIONADO: PRÁTICA PEDAGÓGICO-DISCURSIVA CONSTITUTIVA DA FORMAÇÃO DOCENTE INICIAL NO CURSO DE LETRAS
}

\author{
SUPERVISED INTERNSHIP REPORT: THE EDUCATIONAL- \\ DISCURSIVE PRACTICE CONSTITUENT OF INITIAL TEACHER \\ TRAINING IN THE COURSE OF LETTERS
}

Fernanda Dias de Los Rios Mendonça'

\begin{abstract}
RESUMO: O presente artigo apresenta recorte de tese defendida no âmbito da Linguística Aplicada e visa focalizar, especificamente, as constituiçôes discursivas de professores de língua portuguesa em processo de formaçâo inicial, suas implicaçôes para uma reflexăo propositiva sobre a constituiçăo curricular do curso de Letras do qual emergem tais enunciados e, sobretudo, a funçăo inerentemente formadora do gênero escrito acadêmico em questâo. O desdobramento analítico dos relatórios ancora-se nos aportes teórico-metodológicos bakhtinianos e nos aportes teóricoepistemológicos da Linguística Aplicada atualmente em voga. O primeiro, orienta a metodologia de pesquisa, tomando a escrita dos alunos em sua instância discursivoenunciativa; a segunda, subsidia sobretudo a apreensăo dos enunciados constituídos por compreensôes muito díspares sobre o ensino e o professor de língua portuguesa na educaçăo básica em relaçăo ao que se defende atualmente e se vê legitimado nas diretrizes educacionais voltadas a esse segmento.
\end{abstract}

Palavras-chave: Relatórios de Estágio; Práticas discursivas; Formaçāo docente.

ABSTRACT: This article presents a part of a PhD thesis defended within the Applied Linguistics and aims to focus on the discursive constituents of Brazilian Portuguese teachers in initial training process, their implications for a propositive reflection about the curriculum constitution to Portuguese Language Graduation Course from which teachers enunciations emerge and, above all, the inherently formative function of the academic written genre at issue. The analytical unfolding of reports is anchored on the Bakhtinian theoretical- methodological contributions and on the ongoing theoretical-epistemological contributions of Applied Linguistics. The first guides the research methodology taking the writing of students in their discursive-enunciative instance; the second subsidizes the apprehension of the statements made by very different understandings of Portuguese teaching and Portuguese teacher in primary education related to what is currently being defended and legitimized in educational guidelines aimed to this educational segment.

Keywords: Internship Reports; Discursive Practices; Teacher Training.

Doutora, Universidade Federal do Amazonas. E-mail: fernandadelosrios@yahoo.com.br. 


\section{INTRODUÇÃO}

Tema caro à Linguística Aplicada, a formaçăo de professores de línguas apresenta-se ainda constituído por inúmeros desafios dos quais destacam-se, para fins deste artigo, as práticas discursivas gestadas no interior dos estágios supervisionados e materializadas nos relatórios vinculados a esses componentes curriculares. Motivado por inquietaçōes surgidas durante as leituras e correçôes de relatórios de estágio de observaçấo de licenciandos em Letras de uma universidade federal brasileira, o estudo desdobrou-se à análise dos achados discursivizados nos referidos documentos. Dentre os inúmeros apontamentos enunciados pelos alunos-sujeitos em formaçâo docente inicial, incidiram maior impacto aqueles voltados à apreensăo do ensino de língua portuguesa e ao papel do professor que assume essa disciplina na educaçáo básica, especialmente as valoraçôes a eles implicadas.

Seguindo a diretriz dos resultados alcançados na pesquisa, neste texto, pretendese discorrer sobre os sentidos enunciados nos relatórios de estágio e, também, refletir, à luz dos mesmos resultados, sobre a funçăo precípua que este gênero discursivo deve assumir no âmbito do processo de formaçâo inicial do docente de língua portuguesa, tanto como ferramenta de constituiçăo essencialmente formadora, como enquanto instrumento sinalizador da qualidade da formaçâo em docência oferecida pelos cursos de Letras.

A especificidade da metodologia adotada na pesquisa realizada imputou a necessidade do que Bakhtin (2010a [1979]) denomina "olhar exotópico" da pesquisadora, ou seja, um desdobramento de visâo possível apenas a partir do deslocamento de sua posiçăo inicial de professora dentro do contexto de produçăo discursiva dos relatórios para uma posiçăo mais afastada que permitiu compreendê-los enquanto enunciados de um todo mais amplo, para além do contexto imediato da disciplina de estágio, ou seja, o próprio espaço da esfera acadêmica e o seu contexto formal e ideológico de formaçăo. Sob essa orientaçáo, a compreensâo dos enunciados/discursos é inevitavelmente dialógica, já que pressupóe a presença de seus sujeitos-autores e do sujeito-pesquisador como partes integrantes da produçâo de seus sentidos, através da participaçâo ativa no diálogo em que se inserem (MENDONÇA, 2014). Nessa perspectiva,

[...] meu olhar sobre o outro náo coincide nunca com o olhar que ele tem de si mesmo. Enquanto pesquisador, minha tarefa é tentar captar algo do modo como ele se vê, para depois assumir plenamente meu lugar exterior e dali configurar o que vejo do que ele vê. Exotopia significa desdobramento de olhares a partir de um lugar exterior. Esse lugar exterior permite, segundo Bakhtin, que se veja do sujeito algo que ele próprio nunca pode ver; e, por isso, na origem do conceito de exotopia está a idéia de dom, de doaçáo: é dando ao sujeito um outro sentido, uma outra configuraçăo, que o pesquisador, assim como o artista, dá de seu lugar, isto é, dá aquilo que somente de sua posiçăo, e portanto com seus valores, é possível enxergar. (AMORIM, 2003, p. 14)

O afastamento necessário à análise empreendida permitiu, para além dos questionamentos inicialmente emergentes quando da leitura dos relatórios, entende-los como enunciados constituídos por inúmeras vozes. Vozes essas que definiam a compreensâo e a valoraçâo dos licenciandos sobre o ensino da língua portuguesa e sobre o professor dessa disciplina na educaçăo básica. De fato, 
Cada conjunto verbalizado grande e criativo é um sistema de relaçōes multicomplexo e multiplanar. Na relaçáo criadora com a língua nâo existe palavras sem voz, palavras de ninguém. Em cada palavra há vozes às vezes infinitamente distantes, anônimas, quase impessoais (as vozes dos matizes lexicais, dos estilos, etc.), quase imperceptíveis, e vozes próximas, que soam concomitantemente. (BAKHTIN, 2010a [1979], p. 330)

Assim, o que se pode verificar, na materialidade dos relatórios de estágio, foi um entrecruzamento de acepçóes e ideologias de ensino bastante divergentes entre si, apesar das orientaçōes formais de algumas disciplinas curriculares inseridas no curso em questâo (algumas práticas e os estágios) procurarem voltar a formaçâo dos licenciandos em direçâo às propostas de ensino veiculadas nas diretrizes curriculares nacionais e defendidas em teóricos da LA de reconhecida relevância em nossa contemporaneidade. Tal fato exigiu uma investigaçăo das origens de tais acepçôes advindas, por vezes, de além dos limites físicos da universidade - campo da pesquisa. Essas instâncias enunciadoras aparecem claramente reverberadas nos discursos dos alunos, conforme se poderá verificar. Cabe, no entanto, uma reflexâo prévia acerca do estágio supervisionado enquanto componente formador em que săo produzidos os dados dialógicos analisados.

\section{O PAPEL DO ESTÁGIO SUPERVISIONADO NA FORMAÇÃO DOCENTE}

Conforme destacado em resoluçăo pertinente, "o estágio curricular supervisionado é componente obrigatório da organizaçăo curricular das licenciaturas, sendo uma atividade específica intrinsecamente articulada com a prática e com as demais atividades de trabalho acadêmico." (BRASIL, CNE/CP 02, 2015, Art. 13, § 6º). Ainda consoante à mesma normativa, a relaçấo entre teoria e prática deve manter-se efetiva ao longo de todo o processo formador, a fim de viabilizar o desenvolvimento de conhecimentos e habilidades necessários à docência (idem, Art. 13, § 3). Deste modo, o papel do estágio enquanto componente curricular năo se pode dar em dissonância às demais etapas disciplinares que compóem o curso em razăo das implicaçóes decorrentes da articulaçăo exigida entre domínio teórico, capacidade de reflexăo crítica e açăo prática no campo da educaçăo. Nesse sentido, as etapas de estágio devem complementar de maneira significativa as aprendizagens teórico-práticas que atravessam toda a licenciatura.

A par da relevância efetiva que possui, infelizmente, o que se verifica, em muitas instituiçôes de ensino superior, é, ainda, a perpetuaçăo de estágios demarcados por uma demasiada carga de burocracias, como documentos, fichas de frequências e de avaliaçōes, em detrimento de uma açăo voltada mais ao aspecto transformador que possui, sobretudo pelo privilegiado acesso do licenciando ao campo de trabalho, conforme pontua a legislaçâo, como requisito para garantir ao egresso condiçóes de:

IV - dominar os conteúdos específicos e pedagógicos e as abordagens teóricometodológicas do seu ensino, de forma interdisciplinar e adequada às diferentes fases do desenvolvimento humano;

XIII - estudar e compreender criticamente as Diretrizes Curriculares Nacionais, além de outras determinaçóes legais, como componentes de formaçăo fundamentais para o exercício do magistério. (BRASIL, CNE/CP 02, 2015, Art. 8) 
Seguindo os apontamentos regidos nas diretrizes legais, o estágio supervisionado foi tomado, no âmbito das reflexôes pertinentes à pesquisa realizada, enquanto espaçotempo de fortalecimento de posiçôes, de recriaçăo das dimensôes teóricas vinculadas à realidade escolar de inserçăo, de desenvolvimento de domínio prático e de diversas outras habilidades necessárias à açăo docente no espaço educacional, por meio do enfrentamento dos desafios emergentes em campo, das observaçôes orientadas e dos debates e reflexôes advindos dessas experiências para o aprimoramento do sujeito em formaçâo.

Importa observar que, em contraste com esta perspectiva adotada na pesquisa, o estágio ao qual se vinculam os relatórios analisados, encontra-se ainda sob a fragmentada organizaçăo observaçăo + regência, constituindo o espaço da observaçăo, o Estágio Supervisionado I; e o espaço da regência, o Estágio Supervisionado II. Nessa configuraçấo, segundo o projeto pedagógico do curso (PPC), no estágio observatório, cabe ao aluno acompanhar aulas de docentes na educaçăo básica, à luz das orientaçôes teórico-epistemológicas trabalhadas em disciplinas anteriores, a fim de refletir sobre o cotidiano da sala de aula e sobre as situaçôes dele decorrentes. Para a etapa de regência, pressupóe-se, conforme a modalizaçâo do próprio PPC, que o aluno já esteja mais apto ao exercício docente, em razáo dos aportes e reflexóes desenvolvidos na etapa anterior.

Vale ressaltar que, atualmente, há vasta discussăo a respeito de tal fragmentaçăo, haja vista a defesa de uma maior integraçâo do estágio como um todo, por meio da coparticipaçăo mais efetiva dos licenciandos em diferentes etapas e aspectos da escola, dentro e fora de sala de aula, durante todo o período de estágio. De fato, o que se pode observar, nos relatórios analisados, foi a existência de um distanciamento pouco satisfatório dos alunos em relaçâo à compreensâo da realidade didático-pedagógica observada como se esperava, o que, por outro lado, permitiu a emergência de vozes que se mostraram avessas às orientaçóes trabalhadas com os graduandos em disciplinas afins à prática didático-pedagógica e ao ensino da língua portuguesa.

Esclarecido o contexto imediato das produçôes acadêmicas, faz-se necessária, para a compreensâo adequada dos achados, uma breve discussâo a respeito do relatório de estágio supervisionado como gênero acadêmico inserido na instância de formaçâo inicial do professor de língua portuguesa sob a perspectiva dialógica bakhtiniana.

\title{
OS RELATÓRIOS DE ESTÁGIO COMO GÊNERO ACADÊMICO CONSTITUTIVO DA FORMAÇÃO DOCENTE
}

\begin{abstract}
Os gêneros năo săo enfocados apenas pelo viés estático do produto (das formas), mas principalmente pelo viés dinâmico da produçăo. Isso significa dizer que a teoria do Círculo assevera axiomaticamente uma estreita correlaçăo entre os tipos de enunciados (gêneros) e suas funçóes na interaçáo socioverbal; entre os tipos e o que fazemos com eles no interior de uma determinada atividade social. (FARACO, 2009 [2003], p. 126)
\end{abstract}

Em funçâo de a constituiçâo dos enunciados dar-se pelas limitaçôes e coerçôes dos lugares sociais em que circulam, suas características prenunciam as características desses lugares e das relaçóes que se instituem em seus interiores. Por isso, Bakhtin 
(2010a [1979]) especifica dois grupos de gêneros, de acordo com as esferas a que se associam: os gêneros primários e os gêneros secundários. Os gêneros primários sáo aqueles que decorrem das relaçóes mais casuais e menos institucionalizadas, aos encontros do cotidiano, em que o uso da linguagem se dá de forma mais fluída, pois reflete o "discurso interior". Esses gêneros refletem a ideologia do cotidiano. Os gêneros secundários, por sua vez, decorrem de relaçôes mais formalizadas, sendo o uso da linguagem delimitado pelas especificidades e deliberaçôes do campo em que decorre, refletindo suas ideologias, sua forma de recorte do mundo. Os gêneros secundários refletem as ideologias já constituídas e instituídas socialmente.

Na perspectiva de gênero do Círculo, os relatórios de estágio correspondem a um gênero secundário e seu aspecto híbrido decorre tanto das partes que o constituem como da sua própria natureza temática. As implicaçōes desse gênero săo fundamentais para a perspectiva adotada no estudo, dado que sua relaçăo sócio-histórica, intrinsecamente definida pela sua esfera de inserçâo, é determinante para a compreensăo de sua composiçâo temático-axiológica.

O relatório de estágio supervisionado (RES) consiste num gênero cuja finalidade é fazer o aluno pensar sobre diferentes aspectos do processo de ensino e aprendizagem dos conteúdos pertinentes à sua formaçăo, por meio do registro descritivo da realidade contextual em que se desenrola esse processo, da análise de sua totalidade e do posicionamento crítico em relaçáo aos fatores que o encerram, subsidiado pelos aportes oriundos da graduaçáo. Por outro lado, o estabelecimento do RES como elemento avaliativo, regimentado legalmente e regulamentado no próprio PPC do curso, institui-o de um caráter coercitivo que incide na observância das diretrizes pertinentes à sua produçăo, constantes no regulamento de estágio e nos modelos postulados, por parte dos alunos - estagiários.

Considerando esses fatores intervenientes, os licenciandos e seus relatórios foram considerados no interior da esfera de atividade que integram e que determina a especificidade de suas relaçôes em seu interior. Estando os dados da pesquisa inseridos no âmbito de um campo de atividade específica e de uma determinada temporalidade, entende-se que desse espaço-tempo sócio-histórico-ideológico deriva o fato de que as relaçôes dialógicas, que englobam esses enunciados, refletem a relaçáo entre os interlocutores envolvidos nesse contexto, conforme trata Bakhtin (VOLOCHÍNOV) dessas inter-relaçōes, utilizando-se da metáfora da ilha:

A enunciaçăo realizada é como uma ilha emergindo de um oceano sem limites, o discurso interior. As dimensôes e as formas dessa ilha săo determinadas pela situação da enunciaçăo e por seu auditório. A situaçăo e o auditório obrigam odiscurso interior a realizar-se em uma expressăo exterior definida, que se insere diretamente no contexto năo verbalizado da vida corrente, e nele se amplia pela açăo, pelo gesto ou pela resposta verbal dos outros participantes na situaçăo de enunciaçăo. (BAKHTIN [VOLOCHÍNOV, 2010c [1929], p. 129])

Com essas palavras, Bakhtin (VOLOCHÍNOV) resume a natureza dialógica da linguagem, dizendo que, na elaboraçăo do discurso, anterior ao próprio ato de sua enunciaçâo, o sujeito antecipa-se para organizar seu enunciado, em funçăo do interlocutor para o qual o projeta - isto é, considera a visăo de mundo desse interlocutor, a posiçấo que ocupa na interaçấo dialógica -da relaçăo que estabelece com ele e do contexto imediato em que essa relaçăo acontece. Razăo que justificou considerar, durante a 
análise, que as relaçôes entre os interlocutores dos relatórios (alunos/professores) marcam fortemente suas produçóes, especialmente, pela funçáo primeira para a qual tais enunciados sâo produzidos.

Em outras palavras, teve-se que levar em conta o fato de tais enunciados serem resultado de uma enunciaçáo que se materializa nos RES, cujo objetivo imediato é servir como sistema de avaliaçăo, por parte do docente que ministra a disciplina estágio supervisionado, em relaçăo ao aluno/autor do relatório e que, neste contexto imediato, o interlocutor/professor estabelece uma relaçāo assimétrica com o autor/aluno, estando em condiçấo hierarquicamente superior em relaçăo a esse último. Essa relaçâo particular gera a consequência do alto grau de coercividade que incide sobre a produçăo dos textos, impondo limites restritos às possibilidades de elaboraçăo dos enunciados por parte dos alunos e interferindo, fortemente, na antecipaçáo que o sujeito/ aluno faz (discurso interior) ao elaborar seus dizeres, uma vez que seu papel social, nessa interaçăo, o faz projetar a aceitaçăo do seu dito pelo interlocutor/professor, para elaborar esse dito sobre as diretrizes dessa aceitaçăo. Por isso, a consideraçáo dos sujeitos professores de estágio, interlocutores diretos, aos quais os graduandos dirigem seus relatórios, é tăo importante quanto a consideraçăo desses produtores no contexto de análise dialógica, tornando tăo mais significativos os sentidos materializados nos documentos acadêmicos.

Sem perder de vista essa relaçáo fundamental entre os interlocutores imediatos dos relatórios para a compreensâo de seus sentidos, vejamos o que trazem seus registros.

\section{O QUE REVERBERAM ESSES DISCURSOS?}

Para melhor sistematicidade dos sentidos arrolados nos relatórios analisados, definiu-se focalizar dois fatores de grande reincidência em praticamente todos eles: (1) a estrutura discursiva marcadamente polarizada, acentuando valorativamente os enunciados e (2) o padrăo de professor valorado positivamente.

No que se refere à estrutura discursiva, pode-se apreender que os enunciados constituem-se, de maneira dicotômica, sustentados em dois pilares antagônicos acerca da acepçáo de ensino. Um dos pilares, orientado pela perspectiva veiculada em documentos oficiais, sobretudo os Parâmetros Curriculares Nacionais de Língua Portuguesa; na contramăo deste, uma acepçâo de ensino cunhada pela denominaçấo de "ensino tradicional".

Sabe-se que os Parâmetros Curriculares Nacionais de Língua Portuguesa (PCNs), elaborados na década de 1990, instituem a perspectiva de ensino dessa disciplina "à luz dos usos da linguagem na sociedade em geral", configurando marco institucional na mudança das concepçóes sobre o ensino da língua gestada na década de 1980 (RODRIGUES; CERUTTI-RIZZATTI, 2011. p. 82). Conforme essas autoras:

[...] os PCNs, como documentos institucionais norteadores do ensino e da aprendizagem da língua portuguesa no país, agasalham o processo de discussăo empreendido desde a década de 1980 [...] cujo eixo é a defesa de uma açáo didáticopedagógica na disciplina de língua portuguesa que tenha como ancoragem as práticas de uso da língua na oralidade e na escrita. (RODRIGUES; CERUTTIRIZZATTI, 2011, p. 83) 
O processo de discussăo, a que se remetem as autoras, compôs o que se denominou "a crítica renovadora" ao ensino instrumental e comunicacional da língua instaurado, na década de 1970, que, sustentada por uma concepçáo sociointeracionista, configurouse como oposiçăo ao ensino tradicional e como conjunto de reflexóes acerca de uma nova perspectiva de ensino e aprendizagem da língua. No cerne desse "movimento", estavam as críticas dirigidas ao ensino tradicional, pontuadas por Britto (2008 [1997]) e elencadas nos próprios Parâmetros Curriculares Nacionais de Língua Portuguesa:

A desconsideraçáo da realidade e dos interesses dos alunos;

A excessiva escolarizaçáo das atividades de leitura e de produçăo de texto;

O uso do texto como expediente para ensinar valores morais e como pretexto para o tratamento de aspectos gramaticais;

A excessiva valorizaçăo da gramática normativa e a insistência nas regras de exceçáo, com o consequente preconceito contra as formas de oralidade e as variedades năo-padrăo;

O ensino descontextualizado da metalinguagem, normalmente associado a exercícios mecânicos de identificaçăo de fragmentos linguísticos em frases soltas;

A apresentaçăo de uma teoria gramatical inconsistente - uma espécie de gramática tradicional mitigada e facilitada. (BRASIL, 1998b, p. 18)

Dessa forma, os PCNs propóem uma nova estruturaçăo do ensino e aprendizagem de língua portuguesa, no que concerne às finalidades da disciplina, aos conteúdos e à articulaçâo do processo, cujo ponto de partida e de chegada sáo a produçấo e a recepçâo de discursos pelos sujeitos envolvidos, decorrendo a priorizaçấo das práticas de leitura e escuta e das práticas de produçấo textual, com ênfase na tríade constituída pelo aluno, pelo conhecimento e pelo professor como mediador na potencializaçăo dessas práticas, na contrapartida da perspectiva que aparece sob a acepçâo de "ensino tradicional".

Nos relatórios, as conjecturas que envolvem essas diferentes noçóes de ensino da língua portuguesa sustentam as discursivizaçôes dos licenciandos e, mais do que isso, a valorizaçăo que imputam a cada uma delas, como se pode verificar:

(RES 1) A1: É sempre relevante destacar a importância do ensino de Língua Portuguesa assim como as demais disciplinas, para que os educadores atuais assim como os futuros professores tomem consciência de que fazem parte do processo de formaçâo de crianças adolescentes e jovens, tornando-os cidadăos. É importante que se comprometam com a educaçáo criando métodos adequados a cada necessidade e abandonem de vez os métodos de ensino tradicional. (grifo nosso).

(RES 5) A 5: Assim é válido ressaltar que o processo de ensino-aprendizagem já está sendo trabalhado conforme os PCNs, ou seja, a educaçáo está transformando as pessoas, que antes eram tachadas de serem nâo pensantes, devido ao método tradicionalista, hoje [...] (grifo nosso).

(RES 29) A29: Atualmente, os Parâmetros Curriculares nacionais (PCN's) têm dado direcionamentos plausíveis para o ensino da língua portuguesa com base em concepçōes científicas relacionadas à linguagem, seu funcionamento e funcionalidade. Assim, é importante dizer que o ensino de língua portuguesa nas séries de ensino fundamental e médio citadas neste relatório compartilha de alguns aspectos dos PCN's, entretanto, também está, em muitos pontos, distante desta proposta adotando uma perspectiva tradicional do trabalho dos conteúdos em sala de aula. (grifo nosso). 
Conforme se pode depreender dos excertos transcritos, a dicotomia discursiva sobre as diferentes abordagens de ensino vinculadas aos PCNs e ao ensino tradicional năo apenas apresentam visōes distintas de ensino, mas diferentes valoraçôes sobre esse, por meio da movimentaçăo dialógica que estrutura os enunciados.

O ensino tradicional, embora focalizado em aspectos distintos nas vozes dos alunos, equivale a uma inteligibilidade bastante arraigada na memória histórica e cultural desses sujeitos, em relaçăo ao ensino de língua portuguesa na educaçăo básica, equivalendo a uma "voz persuasiva interior" (BAKHTIN, 2010b [1975]) que atravessa seus discursos - complexificando a arena dialógica que os constitui, em virtude da luta que trava com outras vozes, na disputa para influenciar a consciência do indivíduo - ainda que, em sua maioria, sejam marcados por um movimento dialógico de distanciamento em relaçăo a ela. (RODRIGUES, 2001).

Por outro lado, os PCNs e, consequentemente, a proposta de ensino que veiculam săo tomados, nos enunciados dos licenciandos, como discurso legitimado, oriundo dos conhecimentos teóricos do curso de Letras, portanto, como norteadores do projeto discursivo dos mesmos, que neles se pautam para dirigirem-se às possíveis réplicas do interlocutor/professor que, por representar a instância de onde tais conhecimentos săo positivamente valorados, devem posicionar-se consensualmente a esses dizeres, numa recepçăo assimiladora.

De modo geral, o que se verifica na materialidade enunciativa dos relatórios sâo movimentos dialógicos de aproximaçâo em relaçăo à proposta de ensino veiculada nas diretrizes paramétricas, de um lado, e movimentos dialógicos de distanciamento em relaçấo à proposta de ensino anterior àquela. No entanto, a maior revelaçâo dos relatórios consi stiu no fato de que esses discursos, năo raras as vezes, embora voltem-se para uma valoraçấo positiva sobre a proposta reflexiva de ensino da língua, aparecem fundamentados por argumentos frágeis, sustentados pelo discurso da criatividade, que denunciam a falta de compreensăo da proposta oficial como um todo.

Essa fragilidade se enuncia, nos discursos, pela constituiçăo das inteligibilidades dos licenciandos sobre o ensino de LP ainda arraigadas em discursos ultrapassados, que perpetuam como horizonte apreciativo desses sujeitos, atravessando, sobretudo, sua constituiçăo como professores dessa disciplina.

O discurso da criatividade surge entre a década de 1960 e 1970, a partir de propostas para reformulaçáo do ensino de LP, cujo foco era apenas a necessidade de mudança no "modo" de ensinar, sem considerar o "que" ensinar. "Acreditavase que a criatividade seria condiçăo suficiente para desenvolver a eficiência da comunicaçăo e expressăo do aluno." (BRASIL, 1998b, p. 17). Esse período correspondeu à época em que o quadro teórico-epistemológico em voga constituíase pelas Teorias de Comunicaçăo e pelas Funçóes da Linguagem, cujas influências imputaram a alteraçăo, năo somente no âmbito da disciplina LP, mas no nome da mesma, que se denominou, nesse período, em algumas séries, Comunicaçăo e Expressáo. Na esfera escolar, todas as expectativas de alteraçóes no ensino incidiam sobre o aspecto metodológico e sobre a atuaçăo do professor, nesse período denominado criticamente por Franchi (2006b [1998]) como "espontaneísmo", marcado, segundo o autor, pela atuaçáo pedagógica duvidosa, em que se anulava o papel do professor em proveito do que se considerava criatividade na linguagem năo-verbal. (MENDONÇA, 2014, pp.190-191) 
É exatamente na tentativa de estruturaçâo argumentativa dessas valoraçōes que emerge a figura do professor vinculada a um contexto didático-pedagógico que, segundo os graduandos, caracteriza uma aproximaçáo aos moldes de ensino apresentado nos PCNs e defendidos por eles. Nessa diretriz, pode-se depreender que o perfil docente valorado positivamente caracteriza-se pela capacidade criativa e dinâmica de sua atuaçăo em sala de aula, conforme apontam os excertos abaixo transcritos. Embora as discursivizaçóes permaneçam dicotomizadas entre uma perspectiva tradicional e outra vinculada aos PCNs, essas abordagens de ensino aparecem refratadas na imagem de dois perfis docentes igualmente antagônicos: o tradicional (valorado negativamente) que se sustenta no uso de livro didático, que perpetua um padrăo austero e introvertido; e o ideal (valorado positivamente) que caracteriza-se pela espontaneidade, extrovertimento, ideias inovadoras e dinâmicas.

(RES 10) A10: Ela era dinâmica e extrovertida chegava na sala e conversava com os alunos. Passava os conteúdos de forma didática, sem dúvida adotaria essa metodologia espontânea em minhas aulas, pois dessa forma os alunos participam e conseguem assimilar rápido e facilmente os conteúdos. (grifo nosso).

(RES 23) Aluna 23: No contexto escolar comprovei que cada professor tem um jeito particular de ministrar suasaulas, as professoras AeC săo tradicionais, acomodadas e apegadas ao livro didático, Já a professora B pareceu me entusiasmada, cheia de boas ideias e dinâmicas, procurando fazer a diferencia no ensino da aprendizagem do aluno [...] No caso da professora B substituta, pude observar que ela náo se acomodou, diante da situaçâo das dificuldades encontradas, ministrava suas aulas com bastante empenho e dedicaçăo, fugindo do método tradicional, interagindo com seus alunos, e trazendo para o contexto escolar outras formas de trabalho como, por exemplo, o teatro. (grifo nosso).

Pode-se apreender das citaçóes retomadas que a inteligibilidade desses licenciandos acerca de uma proposta concreta de ensino e de uma práxis docente afinada constituem-se em critérios aleatórios para contextualizar a dinamicidade de uma sala de aula. Nesse âmbito, a valorizaçăo do papel mediador do professor, apresentado nas diretrizes curriculares como elemento fundamental à efetivaçăo de um processo constitutivo de aprendizagem por parte do aluno, aparece silenciado por uma proposiçáo postural dinâmica e criativa, cuja meta final concorre para o alcance de uma aula sem monotonia, divertida e diferente. Em decorrência dessa interpretaçấo, a perspectiva tradicional de ensino apresenta-se falha por constituir-se de uma sequência de procedimentos pré-definidos e nâo por apresentar uma proposta político-ideológica que vai de encontro às necessidades de usos linguísticos emergentes do cotidiano social do alunado para o alçamento de sua cidadania por meio do letramento.

Finalmente, faz-se pertinente ressaltar a reflexăo acerca da figura do professor de estágio no escopo da pesquisa, dada a orientaçâo epistemológico-metodológica bakhtiniana adotada para realizaçâo da mesma. A consideraçáo deste consistiu nâo em sua retomada nos discursos analisados mas em sua participaçăo indireta no processo de produçâo dos discursos materializados nos relatórios, enquanto interlocutor imediato dos mesmos, no sentido de apreender como esse interlocutor previsto/imediato e suas possíveis réplicas influenciam no projeto discursivo desses licenciandos?

A resposta a esta questâo está intrinsecamente ligada ao contexto imediato de produçấo dos relatórios e, sobretudo, à sua funçâo nesse contexto e à especificidade da relaçáo dialógica estabelecida entre os interlocutores envolvidos nessa produçáo, 
conforme mencionado anteriormente. De forma que, considerando a especificidade dessa produçấo discursiva, no contexto da esfera acadêmica, como avaliaçấo parcial da disciplina de estágio e a hierarquia entre o docente (avaliador) e o licenciando, tornase evidente que o projeto discursivo desses sujeitos orienta-se no sentido de alcançar a anuência do interlocutor ao seu dizer. Dessa relaçăo, inferimos, como implicaçăo direta, que os discursos que encontramos materializados nesses relatórios sâo orientados por aquilo que os sujeitos enunciadores acreditam ser apreciado pelos professores de estágio, o que é extremamente significativo para o âmbito da pesquisa, haja vista as reincidências discursivas desses enunciados.

Em outras palavras, percebe-se que o olhar que os licenciandos lançam ao ensino de língua portuguesa e à prática do professor que ministra essa disciplina na educaçâo básica consiste em refraçóes que eles, licenciandos, acreditam ser convergentes ao olhar do professor de estágio, uma vez que, pela perspectiva bakhtiniana, todo discurso dirige-se a um interlocutor, orientando-se para este que, no caso da pesquisa, constitui-se como voz de autoridade a qual deve servir de diretriz aos autores dos relatórios. Razáo pela qual buscou-se descobrir as origens das vozes que atravessavam os discursos dos alunos, uma vez que a orientaçăo do professor de estágio coaduna-se com as diretrizes oficiais e contrapóe-se aos achados discursivizados, movimento que levou a pesquisa tanto à análise da historicidade dessas vozes em temporalidades anteriores, quanto à própria análise curricular do curso.

\section{CONCLUSÃO}

Pode-se afirmar, de modo geral, que a pesquisa aqui retomada apontou que o ensino de língua portuguesa subsidiado pela perspectiva sociointeracional veiculado pelas diretrizes paramétricas vigentes ainda náo se encontra em processo adequado de assimilaçáo por parte dos licenciandos cujos relatórios foram analisados, indicando que a formaçấo docente desses sujeitos, no âmbito do curso de Letras em questăo, apresenta-se ainda superficial no que se refere aos aportes teórico-epistemológicos e ideológicos, como apontou-nos a ancoragem dos enunciados no discurso da criatividade.

Nesse sentido, a perspectiva dialógica adotada no estudo implicou na necessidade de se buscar o porquê de, apesar dos direcionamentos propostos pelos professores de estágio, ainda penetrar no horizonte axiológico dos alunos vozes advindas de uma temporalidade historicamente já ultrapassada. Essa constataçăo a que nos direcionaram os enunciados dos graduandos aponta, para além da experiência escolar desses sujeitos, também para a organizaçăo da grade curricular do curso de Letras em que as disciplinas específicas privilegiadas náo convergem para o preenchimento da lacuna apontada na formaçáo dos mesmos, conforme apontou a pesquisa, por meio da retomada das ementas disciplinares, em que predominam disciplinas da denominada linha dura da linguística como sintaxe, morfologia, fonética e fonologia, em detrimento de disciplinas como linguística aplicada, linguística textual, teorias da enunciaçâo, análise do discurso e sociolinguística, para citar alguns exemplos que năo aparecem contemplados no projeto pedagógico do curso.

Nesse sentido, a contribuiçăo do estudo consiste no apontamento de que se fazem necessárias reflexôes que se orientem para reformulaçôes curriculares que promovam uma formaçấo docente mais consistente e afim às propostas atualmente vigentes para 
a educaçăo básica, em consonância com as orientaçôes normativas para os cursos de formaçâo docente inicial, conforme dispóe o artigo da CNE/CP1 de 2002:

Art. $4^{\circ} \mathrm{Na}$ concepçăo, no desenvolvimento e na abrangência dos cursos de formaçăo é fundamental que se busque:

I - considerar o conjunto das competências necessárias à atuaçáo profissional; II adotar essas competências como norteadoras, tanto da proposta pedagógica, em especial do currículo e da avaliaçáo, quanto da organizaçăo institucional e da gestăo da escola de formaçăo. (BRASIL, CNE/CP1, 2002, p. 2)

Nessa diretriz, o gênero acadêmico relatório de estágio, deve ser concebido para além de sua funçăo avaliativo-burocrática, como um procedimento de reflexăo do licenciando, conforme já mencionado alhures, mas, também, enquanto procedimento institucional auto avaliativo para a reorganizaçăo e a estipulaçăo de ajustes que se façam necessários aos cursos de formaçăo, visando o aprimoramento da formaçăo docente oferecida, em consonância com a percepçăo avaliativa pautada na mesma resoluçấo:

Art. $5^{\circ} \mathrm{O}$ projeto pedagógico de cada curso, considerado o artigo anterior, levará em conta que: I - a formaçăo deverá garantir a constituiçăo das competências objetivadas na educaçăo básica; II - o desenvolvimento das competências exige que a formaçáo contemple diferentes âmbitos do conhecimento profissional do professor; III - a seleçâo dos conteúdos das áreas de ensino da educaçăo básica deve orientar-se por ir além daquilo que os professores irăo ensinar nas diferentes etapas da escolaridade; IV - os conteúdos a serem ensinados na escolaridade básica devem ser tratados de modo articulado com suas didáticas específicas; V a avaliaçáo deve ter como finalidade a orientaçáo do trabalho dos formadores, a autonomia dos futuros professores em relaçáo ao seu processo de aprendizagem e a qualificaçăo dos profissionais com condiçóes de iniciar a carreira. (BRASIL, CNE/CP1, 2002, p. 2, grifo nosso)

Por outro lado, vale destacar o relevante papel do professor de estágio nesse processo, tanto como aquele que orienta o "olhar" do aluno na remodelaçâo das orientaçôes teóricas com base na realidade escolar de inserçâo, quanto como agente de poder transformador, por meio da proposiçăo de açóes que visem sanar problemas de diversas ordens acerca da estrutura curricular diagnosticados na escrita acadêmica dos relatórios de estágio, promovendo melhorias na proposta pedagógica de seu curso de atuaçăo e na sua própria práxis formadora e na de seus pares. 


\section{REFERÊNCIAS}

AMORIM. A contribuiçăo de Mikhail Bakhtin: a tripla articulaçăo ética, estética e epistemológica. In: FREITAS, Maria Teresa; JOBIM E SOUZA, Solange; KRAMER, Sonia. Ciências humanas e pesquisa: leitura de Mikhail Bakhtin. Sáo Paulo: Cortez, 2003, pp.11- 25.

BAKHTIN. Estética da criaçăo verbal. Trad. do russo por Paulo Bezerra. 5. ed. Săo Paulo: Martins Fontes, 2010a [1979].

Questóes de literatura e de estética: a teoria do romance. Traduçăo do russo por Aurora Fornoni Bernardini et al. Sâo Paulo: Hucitec, 2010b [1975].

. (VOLOCHÍNOV). Marxismo e filosofia da linguagem: problemas fundamentais do método sociológico na ciência da linguagem. 14. ed. Săo Paulo. Hucitec, 2010c [1929].

BRASIL. Secretaria de Educaçăo Fundamental. Parâmetros Curriculares Nacionais: terceiro e quarto ciclos do ensino fundamental: língua portuguesa. Brasília: MEC/SEF, 1998b.

. Conselho Nacional de Educaçăo. Resoluçăo CNE/CP1. Brasília, 2002.

. Conselho Nacional de Educaçăo. Resoluçăo CNE/CP2. Brasília. 2015.

BRITO, Luiz Percival Leme. A sombra do caos: ensino de língua x tradiçăo gramatical. Campinas, SP: Mercado de Letras, 2008 [1997].

FARACO, Carlos Alberto. Linguagem \& Diálogo: as ideias linguísticas do círculo de Bakhtin. Săo Paulo: Parábola Editorial, 2009 [2003].

MENDONÇA, Fernanda Dias de Los Rios. Discurso de professores de língua portuguesa em formaçăo: uma análise dialógica de relatórios de estágio supervisionado de observaçáo. 2014. 273f. Tese (Doutorado) - Programa de Pós-Graduaçáo em Linguística. Universidade Federal de Santa Catarina. Florianópolis, 2014.

RODRIGUES, Rosângela Hammes. A constituiçâo e o funcionamento do gênero jornalístico artigo: cronotopo e dialogismo. 2001. 356f. Tese (Doutorado) - Programa de Estudos Pós-Graduados em Linguística Aplicada e Estudos da Linguagem. Pontifícia Universidade Católica. Săo Paulo, 2001.

;CERUTTI-RIZZATTI, Mary Elizabeth.Linguística Aplicada:Ensino e Aprendizagem de Língua Materna. Florianópolis: DLLV-CCE-UFSC, 2011. 